\title{
Oralidad y representación. La otra voz en la narrativa de Ciro Alegría ${ }^{1}$
}

\author{
MANuel LaRrú \\ Universidad Nacional Mayor de San Marcos \\ larrusal@ec-red.com

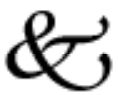

Resumen

Este artículo se propone estudiar la funcionalidad de los relatos de tradición oral que narran los personajes populares de las novelas de Ciro Alegría. Se considera que la intercalación de estos textos, más allá de generar el suspenso (como propone Tomás Escajadillo), o poner en evidencia la intensa verosimilitud del universo representado - al ser un tipo de cuentística típica del referente que Alegría representa literariamente (como señala Antonio Cornejo Polar) - tienen como función la construcción de un sujeto heterogéneo y popular distinto al narrador monológico y grafocentrista. En tal sentido, siguiendo a Huaytán Martínez, se propone que la incorporación en estas novelas de relatos de raíz oral establecen vasos comunicantes entre la narrativa indigenista de Ciro Alegría y el género testimonial.

Palabras clave: Ciro Alegría, indigenismo, relatos folklóricos, oralidad.

\begin{abstract}
In this article, the functionality of oral tales coming from the mouth of Alegría's popular characters (which the author includes in his novels) is studied. It is alleged that these texts perform another function besides generating suspense (as Escajadillo proposes) or offering evidence of verosimilitude of the universe, presenting typical referents from this world, whose taletelling Alegría gives a literary form. This function is the building of a popular and heterogeneus subject different from the monologue-centered narrador. Following Huaytán Martínez, the articu-
\end{abstract}

1 Este ensayo fue originalmente una ponencia presentada en el Simposio Nacional «Cien años con Ciro Alegría. La vigencia del indigenismo». Una primera versión apareció en la Revista «Tinkuy» №1, primer trimestre 2010. El texto ha sido revisado y ampliado gracias a la Srta. Sara Viera Mendoza, cuya investigación y aportes han sido fundamentales en la consolidación del presente artículo. 
list thinks that these texts link Alegría's indigenist narrative to the testimonial genre.

Key words: Ciro Alegría, Indigenism, Folk-Tale, Orality.

A cien años de su nacimiento, a setenta años como promedio de su «Trilogía novelística clásica», como denomina Antonio Cornejo Polar a sus tres grandes novelas, ¿de qué manera es actual Ciro Alegría?

Desde luego, hay diversos aspectos en el nivel temático —ideológico, y también en el modo de la representación, en el ámbito retórico, ya ampliamente superados. Por ejemplo, la oposición casi esquemática entre gamonales e indígenas, la presencia de una naturaleza indomeñable o el empleo de un narrador que controla perfectamente el universo representado.

Es verdad también que se pueden leer las novelas de Ciro Alegría en clave metafórica, y encontrar que Rumi, la comunidad de El mundo es ancho y ajeno, sigue dando la batalla, ahora, ante un poder que los trata como ciudadanos de segunda clase y los tilda de perros del hortelano por no dejarse dominar por los nuevos Álvaro Amenábar, que aparecen, en estos tiempos, reciclados, portando el estandarte de una modernidad periférica o como representantes de voraces trasnacionales. Del mismo modo, el friaje que hace algún tiempo causó decenas de muertes, particularmente entre los niños de la alta puna peruana, puede ser comparable a la terrible sequía que narra nuestro escritor en Los perros hambrientos, y así sucesivamente, es posible que un lector curioso pueda encontrar analogías.

Este tipo de comparaciones que también aluden a la actualidad de Alegría, en el fondo lo que están demostrando es el modo cómo, décadas después de su gran obra novelística, se ha ido expresando, imponiendo y desarrollando un tipo de modernidad en el Perú.

En este ensayo, nos interesa otra mirada, nos referimos a la recurrencia del relato "folklórico», de raigambre claramente oral, que utiliza con profusión en sus tres novelas Ciro Alegría.

Cuando se interroga sobre los mecanismos de la representación, 
Gayatri Spivak ${ }^{2}$, señala dos niveles de la misma: En primer lugar, el nivel ideológico, que atañe a la acción de hablar por alguien. Esta dimensión implica que el narrador asume un rol de intermediación entre el lector y el referente, aspecto muy notorio no solamente en el indigenismo ortodoxo, como nombra Tomás Escajadillo a la narrativa andina de Ciro Alegría ${ }^{3}$, sino también evidente en la llamada novelística de la tierra, novela regionalista, mundonovista, etc., en la que el autor asume el rol de orientador social y además, en términos políticos, busca denunciar o encabezar las luchas del pueblo contra la oligarquía o la penetración imperialista.

En segundo lugar, la representación se asocia con el aparato retórico, esto es, el modo cómo el narrador refiere, narra algo acerca de alguien.

En Ciro Alegría — aspecto subrayado unánimemente por la crítica- hay en el ámbito de la representación una clarísima voluntad de verosimilitud, como lo propone nuestro autor cuando hace hablar a personajes que narran cuentos «folklóricos»

«Si, pué — dice don Matías - cosita que quisiera saber es la muerte e los pajaritos. Nunca mei encontrao nuño muerto puel campo salvo al que lo haiga desplumao una culebra (...) pero entón se nota. Muerto po su muerte mesma nunca $»^{4}$.

A partir de este enunciado de don Matías, Silverio Cruz nos contará un relato que desarrolla su interrogante: ¿dónde van a morir las aves?, cuento que más adelante referiremos. En lo que acabamos de leer hay algo que «salta a la vista». La dificultad misma de la lectura. No estamos ante una secuencia sintáctica «normal», que haría más fluida y rápida la lectura. El ojo demora en recorrer cada línea, reconociendo cada palabra, como si se enfrentara a una especie de orografía discursiva encabritada, que requiere lentitud para identificar las palabras, término por término. ¿Por qué ocurre esto?

Porque se trata, desde luego, de textos para ser «escuchados» antes que para ser leídos, inclusive uno puede imaginarse el tono de voz, el timbre, el dejo de don Matías al contar su relato, y es que aquí

2 SPIVAK, Gayatri. «¿Puede hablar el sujeto subalterno?». En Orbis Tertius, Año III, № 6, 1998.

3 ESCAJADILLO, Tomás. Narradores peruanos del s. XX. Lima, Ed. Lumen, 1994.

4 ALEGRÍA, Ciro. La serpiente de oro. Lima, Planeta, 2007. 
se impone la voz antes que la letra. Estamos pues, y valga el oxímoron, ante una oralidad escrita.

La voz que aparece en esta necesidad de mimesis del narrador, implica una voluntad de dar existencia, de afirmar la identidad de alguien. Y es que la voz, como nos lo recuerda Paul Zumthor ${ }^{5}$, es una cosa primera, hecha de tono, timbre, fuerza que está dada antes, inclusive, de la palabra. Ella, la voz, por sí misma tiene un valor simbólico en tanto «vive» y se encuentra alojada en el cuerpo. El lenguaje oral es impensable sin la voz. La voz es originaria. En latín os, oris significa boca, pero también origen. Aun cuando en la escritura resulte difícil rescatar las modulaciones completas de la voz, éstas pueden ser imaginadas; se diría que es posible entrever la gesticulación y la situación de oralidad que rodea la actuación vocal de don Matías, en este sentido, la voz es recipientaria de la palabra.

Pero hablar supone escuchar. Implica una doble actuación basada en un entendimiento tácito y activo. Por eso, el oyente asume, más que en la escritura, una forma de adhesión a lo dicho. La empatía, la dimensión agonal de intercambio forman parte de su actuación. Son numerosos los ejemplos que pudiéramos entresacar de la narrativa de Ciro Alegría para demostrar la coparticipación del oyente en la construcción del relato.

Sin embargo, conviene destacar todavía algunas otras características de la oralidad, centrada en la voz, y que utiliza Ciro Alegría de un modo magistral, no con función meramente decorativa, sino como un aspecto esencial de la estructura narrativa misma.

Walter Ong señala que las palabras son sucesos, están animadas, son por lo tanto modos de acción que producen reacciones en el receptor, quien, a su vez, interactúa con el narrador.

Recordar es saber, y se recuerda sólo lo memorable porque el lugar que contiene el conocimiento es el cuerpo, personal y colectivo, esto es, la tradición. Si bien el rol de la memoria colectiva es importante, en tanto actualiza el recuerdo de esa «historia otra», el recurrir a esta no implica la adquisición de lo que significa «saber» en

5 ZUMTHOR, Paul. Introducción a la poesía oral. Madrid, Ed. Taurus, 1991. 
la comunidad andina. Al respecto, Grimaldo Rengifo ${ }^{6}$ señala que el saber como entidad separada de la vida no existe, para saber hay que ver, hay que vivir. En este modo de ver el mundo no existe separación entre la comunidad humana y la naturaleza, sino que ambas están articuladas. Por eso en la comunidad andina las historias contadas están respaldadas por las vivencias de otros y poseen un nivel de realidad. No es casual que en las narraciones se insista en su autenticidad citando lugares, a la persona que lo contó, dando detalles del momento y del lugar en el que ocurrieron los hechos.

Cuando Matías pregunta ¿cómo es la muerte de los pajaritos? recibe dos tipos de respuestas. Melcha le responde: «Son cosas e Dios, cristianos... ¿Quién sepa?». Mientras que Adán le dice: «Yo digo que los señores, esos letraos quiay po los pueblos, esos nomá saben». Ninguna de estas dos respuestas satisface a Matías, más bien cuestiona la autenticidad del saber de los letrados y los pone en duda porque ellos no lo han visto ni lo han vivido: «Esos dicen que saben, pero nues lo mesmo que saber e verdad quiaberse dao cuenta con los meros ojos diuno».

Estos relatos llenos de significación condensan el saber cultural que, en determinadas circunstancias, se comunican entre los miembros de una comunidad para dar cuenta del mundo en que se vive. El cuento andino, y con ello la abundancia de relatos populares que actualiza Alegría, justamente tienen un común denominador: el saber que trasmite el narrador comporta una ética, un modo de actuación en la realidad, una manera de aprender a orientarse socialmente.

El relato andino tiene, entre una de sus funciones más importantes, un efecto endoculturador. De esta manera, los personajes populares que narran al interior de sus novelas no desarrollan temas de manera arbitraria, sino que establecen modos de conocimiento acerca de esa realidad o reproducen estéticamente las normas que articulan a la comunidad.

Incluso si alguien viene de fuera y se inserta en la comunidad debe adecuar su forma de vivir y pensar al modo de ver la realidad

6 GRIMALDO RENGIFO, «El saber en la cultura andina y en occidente moderno». En Cultura andina agrocéntrica. Greslou et al. Lima, PRATEC, 1991. 
de los lugareños. Ese es el caso del ingeniero Osvaldo quien una vez estando en Bambamarca quiso salir de noche y el gobernador Aristóbulo se lo impide porque es la noche en que «la quemada» sale a penar por el pueblo. Haciendo caso omiso Osvaldo sale, pero al instante regresa por el miedo que siente al escuchar las fuertes ráfagas de viento y ver la negrura espesa de la noche. Después que Aristóbulo termina de relatarle la historia quedó tan sorprendido que «a medianoche me desperté sobresaltado y creía escuchar gritos y quejas por el pueblo (...) pero palabra que parecía escuchar el llanto de una mujer...».

Las experiencias vividas en un mundo distinto al suyo terminan por convencerlo: « iTodo esto es tremendo! He pasado muchas cosas (...) lo que he visto y lo que he oído... », terminan por atraerlo a la forma de vida de los indios y cholos: «Bah don Oshva quien apriende a coquiar puacá se queda. La coca lo guielve onde uno cristiano destos valles y destas punas » $\mathrm{y}$, además, volviéndolo un portador de la cultura del lugar: «Cuente, don Oshva, a ver cuentiusté -reclama el viejo. (...) ¿Saben ustedes? La quemada fue una mujer a la que hicieron morir en la hoguera (...) Bueno; en el pueblo estaba de cura un tal Ruiz...».

El mundo narrado por Ciro Alegría a través de alguno de sus cuentistas, llámese Simón Robles, Silverio Cruz o el anciano Matías, entre otros narradores populares que construye, sea en Los perros hambrientos o en La serpiente de oro, por ejemplo, es un mundo conocido, frecuentado, caminado por el receptor inmediato de estos cuentos, es decir, el comunero indígena.

En esta perspectiva Walter Ong7, nos recuerda que la oralidad posee una cualidad homeostática, en otras palabras, no sólo hay una relación biunívoca entre lo referido y el receptor, sino que el relato se actualiza en un presente permanente; lo sabido, lo conocido se conecta con el mundo inmediato. En tal virtud, cuando lo arcaico se disocia con el presente pierde sustancia, pierde referencialidad, se torna inútil, se olvida.

7 ONG, Walter. Oralidad y escritura. La tecnología de la palabra. México, FCE, 1987. 
Pero, ¿qué es lo que se recuerda?, ¿qué vale la pena de ser narrado? Por supuesto, lo memorable, como por ejemplo, las proezas públicas de personajes del mundo humano, animal, sobrehumano, sobrenatural, etc.; puesto que en torno a ellos se organiza el saber que se transmite. La palabra vocal, que relata, no es por ello arbitraria, su función es, lo reiteramos, plenamente endoculturadora.

El recordar y contar determinados acontecimientos requiere apelar a fórmulas y mecanismos retóricos. El relato oral, en este sentido, es claramente formulaico. Por eso es bastante común que los narradores para relatar sus historias se apoyen constantemente en el estilo aditivo: "Yel diablo les vendía cobrándoles precio, yal paquetito blanco lo reparaban y naides liacía caso...», en el uso de conjunciones asertativas o negativas, así también la apelación a proverbios: «al burro y la mujer palo con ellos», en las frases hechas que sirven para cambiar la linealidad de la narración: «yentón, yeneso, yaita, yasies» y en los dichos populares que da cuenta nuestro autor.

Otro aspecto que nos parece importante resaltar es la relación entre la habilidad de contar historias con el acto de hilar: " y Simón retomó el hilo de la charla, sea por dar curso a sus aficiones de narrador, sea por romper ese silencio triste (...)» ${ }^{8}$. Denise Arnold y Juan de Dios Yapita ${ }^{9}$ sostienen que la relación entre la práctica textual y la dinámica del tejer es audio-oral. La destreza para manipular un discurso está estrechamente relacionada con ciertas formas de composición como en el tejido. En el ritmo, las repeticiones, el entrelazar las frases para ir armando la trama, en el cruzar un elemento en relación con otro, etc.

La oralidad empleada por los narradores revela el entramado de las historias y la forma como son «tejidas». Así tenemos que un buen narrador contará su historia con un determinado ritmo: «Y con su natural habilidad de narrador, callose para provocar un expectante silencio (...) los que ya lo conocían se aprestaban a escucharlo con

8 ALEGRIA, Ciro. Los perros hambrientos. Lima, Peisa, 2001.

9 ARNOLD, Denise [y] Juan de Dios, YAPITA. «Las canciones a los animales en un ayllu andino: hacia la arquitectónica textil de un texto oral». En Tradición oral andina y amazónica. Juan Carlos Godenzzi (Comp.). Cusco, CBC, 1999. 
gusto, pues el Simón sabía agregarle algún detalle nuevo cada vez», no apurando la trama -recordemos que el mismo acto de tejer implica una cierta tensión entre el tejer bien cuando se hace con paciencia y el tejer mal cuando se realiza apurado. Una buena trama es aquella que es realizada con ese gusto, tono y paciencia que caracteriza al narrador andino- y por último, sabe complicarla relacionándola con el mismo sentido de la vida «que a veces tiene acentos de fábula (...) todues enredao y no se ve, como la punta el hilo en la madeja, pero ay ta... Sólo que la madeja ta muy grande...».

En sus relatos los narradores orales no apelan a ejemplos abstractos, y es que la oralidad está intensamente territorializada. Esta se hace palpable en la interacción de lenguas o bilenguajeo ${ }^{10}$ presente en sus novelas. La evidencia del poco dominio del español hablado por parte de los personajes en las novelas de Ciro Alegría, nos permite deducir que el castellano no es su lengua nativa, antes bien es posible argumentar que existe un contacto entre lenguas debido a las fracturas de la lengua hegemónica, que en este caso es el castellano, de ahí que la competencia de su castellano sea pobre y casi ilegible a los ojos del lector.

Lo expuesto se corrobora en ese lenguajeo hibrido, popular, empleado por los personajes donde la influencia es tanto del quechua oral como del español. Así lo manifiesta el mismo narrador de Los perros hambrientos:

Tinto fue reemplazado en sus tareas por Shapra. El nombre vínole a este de pelambre retorcido y enmarañado, pues shapra quiere decir motoso. (En el lenguaje cholo, algunas palabras keswas superviven injertadas en un castellano aliquebrado que sólo ahora comienza a ensayar su nuevo vuelo).

Este bilenguajeo también refleja el surgimiento de una lengua nueva «la de las tierras fronterizas. Allí, en el punto donde se encuentran las culturas» ${ }^{11}$. Este nuevo lenguaje — definido como el hablar, pensar y escribir desde el interior de una lengua- es el reflejo de un

10 MIGNOLO, Walter. Historias locales/diseños globales. Colonialidad, conocimientos subalternos y pensamiento fronterizo. Madrid, Akal, 2003.

11 Ibidem. 
modo de ser y existir propio de quienes viven en las fronteras, en la interacción subalterna de dos lenguas, que les permite ser narradores de su propio discurso, pero que también los aísla confinándolos a la periferia por no dominar la lengua principal.

Retomando el relato de don Silverio Cruz, uno de los cuentistas de La serpiente de oro, que responde la pregunta de don Matías sobre dónde mueren las aves, él recurre, para dar respuesta a su interrogante, a su más antigua tradición.

Escuchémosle:

"-Cuanduera muchacho mi máma contabuna historia quella loyó tamién cuando muchacha (...) Dicen quiun cristiano se jué a cortar leñita».

Así comienza Silverio y narra cómo este cristiano al perderse en medio del bosque vio que los pájaros iban ascendiendo hasta el pico de los árboles y uno de ellos, que tenía las plumas ajadas, comenzó a volar y a ascender y ascender hasta perderse entre las nubes mientras era despedido por las demás aves.

«Yeneso los pajaritos vieron ondel cristiano, yuno dellos voló pa una rama cerca dél y dizque habló como si juera otro mero cristiano: yas visto lo que niun cristiano ve. Si cuentas mueres».

Al terminar su relato, otro personaje, Arturo, interviene:

"Güieno, pero siel cristiano no pudo contar, y nua contao como dices, ¿cómo va ver sabido dispués?»

Esta cita nos sirve para detectar otra característica básica del relato oral: no pueden contarse como si fueran monólogos. Bruce Manheim ${ }^{12}$, en su estudio "Hacia una mitografía andina», sostiene que el narrador no sólo necesita de un público determinado - y no cualquier público-, porque éste interviene no sólo en la reconstrucción textual, sino que el conocimiento cultural, que el narrador transmite y da forma, está fragmentado y en debate. En la actualización del

12 MANHEIM, Bruce. «Hacia una mitografía andina». En Tradición oral andina y amazónica. Juan Carlos Godenzzi (Comp.). Cusco, CBC, 1999. 
relato se dan a conocer los «mundos culturales» del narrador y el oyente, cotejables en el habla común, la evidencialidad y el repertorio del discurso.

En la narración quechua se requiere, entonces, la participación activa del oyente, que interviene con diversas señales de asentimiento, repetición de frases, ejecución de preguntas o comentarios adicionales tal como lo hace Arturo al dudar del relato de Silverio Cruz.

Esta estructura coparticipativa — sostiene Mannheim - implica que la autoridad del narrador hablante no se da por sentada, sino que se establece social y gramaticalmente por medio de evidenciales. En otras palabras, no existe narrador autorizado final, como ocurre en la escritura, ni tampoco hay intérprete autorizado final. Es por eso que cuando algunos de los narradores cuentan una historia apelan a la autoridad de la colectividad recurriendo a la memoria colectiva y con esta operación también trae su imaginario social y pensamiento cultural.

Lo que cuentan los narradores populares en la novelística de Ciro Alegría, posee plenamente las características que hasta aquí hemos venido señalando, cuyo sentido es más fácil de ser interpretado gracias a la investigación contemporánea acerca del relato conversacional y de la psicodinámica de la oralidad.

¿Cuál es la razón fundamental de esta necesidad de verosimilitud con cuentos cuya interpolación, en el hilo narrativo principal, esto es, la técnica de la acción retardada (como lo ha señalado Tomás Escajadillo), busca generar suspenso?

En nuestra perspectiva, quien logra una explicación sólida y convincente es Antonio Cornejo Polar en su texto La trilogía novelística clásica de Ciro Alegría ${ }^{13}$. Propone el estudioso sanmarquino que «los cuentos populares que narran en su propio lenguaje algunos personajes (...), que son reproducidos por el narrador con puntillosa intensión documental, bien pueden ser considerados transcripciones de cuentos folklóricos». (p. 85). Y es que este tipo de cuentos

13 CORNEJO POLAR, Antonio. La «Trilogía novelística clásica» de Ciro Alegría. Lima, Latinoamericana Editores, 2004. 
pertenece, como el propio texto documenta, al sistema literario popular andino.

A esto responde - afirma Cornejo Polar- la incorporación de formas cuentísticas portadoras de una voluntad de abrir el canon novelesco — canon ajeno a los modos de narrar andino, acotamos nosotros- para dar cabida al ejercicio de otras formas que sí tienen representación en el mundo representado de la novela.

En efecto, la forma típica de la narración en el mundo andino no es la novela, de raíz europea y ajena por ende a los modos de ficcionalización oral. La forma típica es el relato que llamaríamos «folklórico» (utilizando la terminología que emplea Cornejo Polar), o el que posee una dimensión sagrada, dimensión que encarnan figuras paradigmáticas y que suelen ser conocidos como relatos míticos.

En cuanto al narrador principal, el que se asocia con el autor Ciro Alegría, éste se sitúa en ambos mundos, el del lector urbano y el del referente indígena, ocupa el lugar de la intersección deviniendo, afirma Cornejo Polar, «en una especie de intérprete y de testigo del mundo cordillerano». Por lo tanto, el lector acepta como propia de ese universo andino «la norma linguística de los narradores populares como un aspecto más del testimonio verista del narrador y como la única posibilidad de presentar la realidad del mundo novelado» ${ }^{14}$.

En su reciente tesis, provocadora de nuevas calas críticas y demostraciones, Eduardo Huaytán Martínez propone al testimonio andino como la continuidad del indigenismo, llámese ortodoxo o neoindigenismo.

En efecto, esa voluntad tan marcada en Ciro Alegría de transcribir relatos apelando al modo de hablar, a la voz de los personajes, lo ubica en el lugar del gestor testimonial, de aquél que suele ser denominado el «intelectual solidario», que es quien presta su capacidad letrada para dejar oír la voz del otro. Este autor implícito se muestra solidario e interactúa dialógicamente con los subalternos en un proceso dinámico de intercambio que los libera de su silencio y los muestra como personajes autónomos.

14 Ibídem, p. 87. 
El uso de la oralidad que produce el registro de la voz genera el efecto de realidad-verdad, o efecto documental según la propuesta de Hugo Achugar ${ }^{15}$. Por ende, el recurso de mimar la voz del otro hace que el lector asuma como auténtico, como verídico ese discurso.

Necesariamente el testimonio involucra la presencia de un interlocutor (gestor) y un testimoniante (testor). Este encuentro se produce dentro de un mismo espacio social y supone un diálogo, pero desde posiciones diferentes por la distancia que existe entre ambos: intelectual/activista, extranjero/indígena, oralidad/escritura. Este dialogismo, al que hemos aludido, esta representado en las novelas de Alegría y lo reconocemos en la doble enunciación, el de sus narradores folklóricos llámese Matías, Silverio Cruz, Simón Robles, etc. y el del autor implícito que hace el papel del gestor en la práctica testimonial.

Así, tenemos un sujeto que utiliza formulas, palabras, dichos e historias para construir un texto original emitido desde otra tradición. Estos narradores populares hablan desde otro lugar de enunciación recurriendo siempre a los saberes adquiridos en experiencias anteriores, es decir a la memoria colectiva. "Me contún señor quen tiempos antiguos los peruanos adoraban comua meros dioses al río tamién y tamién a la serpiente». Es evidente que los relatos narrados por los personajes no son propiedad del autor implícito porque es un conocimiento que esta fuera de su competencia y de su espacio socio cultural, por lo tanto pertenecen al campesino indígena. Esta operación genera la construcción de un «yo» popular que además de representarse así mismo también representa a «otros». Entonces este sujeto plural hablará en nombre de la comunidad a la que pertenece.

Lo contado por estos narradores nos recuerda la vida de quienes padecen opresión, injusticia social, sufren el abuso de los militares y son confinados a permanecer en los márgenes de la sociedad. Ese el caso de Mateo, yerno de Simón Robles, cuando es capturado

15 ACHUGAR, Hugo. «Historias paralelas / historias ejemplares. La historia y la voz del otro». En Revista de Crítica Literaria Latinoamericana № 36. Lima, 1992. 
y obligado a abandonar a sus hijos y a su esposa para cumplir el servicio militar.

Los gendarmes llevaban enormes fusiles y estaban uniformados de azul y franjas verdes. Sin más le preguntaron a gritos:

—_onde esta tu libreta?

El Mateo no respondió. El que llevaba galones gruñó.

—iTu libreta e conscrición melitar! (...) Él Mateo no entendió bien, pero recordaba que a otro indio de la ladera del frente lo llevaron hacía años por lo mismo (...) atinó a responder:

- Ay en la chocita, puestará... y echó a andar seguido de los cacha$\cos (. .$.$) tuvo que seguir hacia el bohío y entrar. Salió acompañado$ de la Martina (...) ella con las manos juntas, en alto, llorando e implorando:

—Nuay libreta taititos, ¿dionde la va sacar? ¿No lo lleven, taititos? ¿Qué será de nosotrus? Taititos, dejénlo...

Uno de los gendarmes bajó del caballo y le dió una bofetada, tirándola al suelo, donde la Martina se quedó gimiendo y lamentándose. El Mateo amarrado por las muñecas, los brazos a la espalda fue llevado a prisa.

Este sujeto de enunciación y de un enunciado otro se presenta como un testigo que cuenta lo que ve enfatizando en su discurso: los problemas, los abusos y las penurias que pasan los que viven en su comunidad. En Los perros hambrientos los pobladores deben soportar a un hacendado prepotente que los despoja de sus propias tierras y los condena a vivir una vida miserable.

En este contexto es que escuchamos los pedidos y súplicas de Simón Robles al hacendado don Cipriano cuando sobrevino la sequía y no tenían nada para comer: «un poco de cebada patrón (...) tengasté piedá (...) sus mulas y caballos finos tan comiendo cebada. ¿No vale mas quiun animal un cristiano? (...) hoy es el caso que debe matar pa que coma su gente. Peyor que perros tamos... Nosotrus sí que semos como perros hambrientos».

Este «nosotrus» representado en la voz de Simón Robles trae a colación los problemas y conflictos del testimonio acerca del quién 
habla, para qué lo hace y desde qué posición enuncia. En este caso es la voz de un oprimido quien se alza para reclamar los atropellos de una clase privilegiada. De ahí que lo dicho por Simón cumpla con la función denunciatoria del testimonio y al mismo tiempo cuestionadora de quienes ostentan el poder. En este sentido los sucesos guardados en la memoria de estos narradores sirven para construir la historia desde otra versión, la de los silenciados.

Si bien esto es palmario, nosotros consideramos que este modo de construir relatos andinos, que utiliza Ciro Alegría, va más allá del afán verista, de recurrir a la acción detenida para generar suspenso o de persuadir al lector de que este es el modo «literario» natural de narrar del poblador andino. Aunque todo esto es correcto, en propiedad lo que está haciendo el autor es presentarnos historias alternativas a la hegemónica y monológica de la ciudad letrada.

La identidad que estos cuentos "folklóricos» construyen no es homogénea. Como en el testimonio, estamos ante personajes que cuentan una historia otra, con una voz otra, distinta a la hegemónica que utilizaba el narrador grafocéntrico y autorizado.

En este ensayo se demuestra que la modalidad de emplear una serie de narradores se distingue al otro perteneciente a un sistema cultural distinto al occidental.

Este paralelismo que proponemos con el género testimonial nos ayuda a comprender que la estrategia narrativa que emplea Ciro Alegría, supone la construcción de un sujeto y una historia heterogéneos. Oír esa voz que aparece en sus novelas, implica un claro desmontaje del discurso homogenizador del poder. En la perspectiva de este ensayo, es allí donde radica la plena actualidad de este clásico de las letras peruanas.

En la tradición andina abundan cuentos que tienen origen escrito. En un medio híbrido, pluricultural, de fronteras porosas entre escritura y oralidad, como es el universo andino, no existe oposición entre ambas tecnologías comunicativas; más bien ambas se autorreferencian, interactúan o sirven de base para una performance oral o escrita. 
Así como Ciro Alegría usa la oralidad para escribir cuentos de estirpe "folklórica», también en la narrativa oral hay relatos cuyo origen se puede rastrear en la escritura, en los libros, y que al paso del tiempo se han incorporado a la tradición de las comunidades. Ello, una vez más, nos demuestra la dimensión heterogénea y transcultural no sólo de la narrativa escrita de corte indigenista sino también de la oralidad que con tan buena salud sigue cultivándose en los Andes.

\section{Referencias bibliográficas}

ACHUGAR, Hugo (1992): «Historias paralelas / historias ejemplares. La historia y la voz del otro». En Revista de Crítica Literaria Latinoamericana № 36. Lima, Latinoamericana editores.

ARNOLD, Denise [y] Juan de Dios, YAPITA (1999): " Las canciones a los animales en un ayllu andino: hacia la arquitectónica textil de un texto oral». En Tradición oral andina y amazónica. Juan Carlos Godenzzi (Comp.). Cusco, Centro Bartolomé de las Casas.

CORNEJO POLAR, Antonio (2004): La «Trilogía novelística clásica» de Ciro Alegría. Lima, Latinoamericana Editores.

ESCAJADILLO, Tomás (1994): Narradores peruanos del s. XX. Lima, Ed. Lumen.

HUAYTÁN MARTÍNEZ, Eduardo (2009): “El testimonio sur-andino: reformulación de la representación de la narrativa indigenista. El caso de los testimonios de los artistas andinos”. Tesis. Lima, UNMSM.

MANHEIM, Bruce (1999): «Hacia una mitografía andina». En Tradición oral andina y amazónica. Juan Carlos Godenzzi (Comp.) Cusco, Centro Bartolomé de las Casas.

MIGNOLO, Walter (2003): Historias locales/diseños globales. Colonialidad, conocimientos subalternos y pensamiento fronterizo. Madrid, Akal.

ONG, Walter (1987): Oralidad y escritura. La tecnología de la palabra. México, Fondo de Cultura Económica. 
RENGIFO, Grimaldo (1991): «El saber en la cultura andina y en occidente moderno». En Cultura andina agrocéntrica. Greslou et al. Lima, PRATEC.

SPIVAK, Gayatri (1998): «¿Puede hablar el sujeto subalterno?». En Orbis Tertius, Año III, № 6.

ZUMTHOR, Paul (1991): Introducción a la poesía oral. Madrid, Ed. Taurus. 